\title{
Cryopreservating Human Dental Pulp Tissue at Tooth Extraction for Later Culturing Proliferative and Multipotent Cells
}

\section{Ming Yan}

Universitatsklinikum Hamburg-Eppendorf

\section{Lingling Fu}

Hebei Medical University

\section{Lan Kluwe}

Universitatsklinikum Hamburg-Eppendorf

\section{Xiangjun Li}

Hebei Medical University

\section{Guiyun Ren}

Hebei Medical University

\section{Ralf Smeets}

Universitatsklinikum Hamburg-Eppendorf

\section{Martin Gosau}

Universitatsklinikum Hamburg-Eppendorf

xiao liu ( $\square$ liuxiao2813@outlook.com )

Hebei Medical University https://orcid.org/0000-0003-3463-3423

\section{Research article}

Keywords: dental pulp cells, differentiation, dental pulp tissue, dimethyl sulfoxide (DMSO), cell culture, tissue cryopreservation, osteogenic differentiation, adipogenic differentiation

Posted Date: May 7th, 2020

DOl: https://doi.org/10.21203/rs.3.rs-26388/v1

License: (c) (i) This work is licensed under a Creative Commons Attribution 4.0 International License.

Read Full License 


\section{Abstract}

Background Teeth extracted are usually disposed as bio-waste whereas they could serve as an autologous tissue for culturing multipotent dental pulp cells which have application potential in regenerative medicine. The present study aims to examine the feasibility of cryopreservating dental pulp tissue at teeth extraction for later culturing cells.

Methods The pulp tissue from each of a total of 10 teeth were cut into small fragments which were then divided into two portions. One portion was directly used for culturing pulp cells using the explant method. The other portion was cryopreserved with 10\% DMSO in liquid nitrogen for at least one month and then thawed for culturing pulp cells.

Results Vital cells were obtained from all the 10 pulp fragment suspensions which went through cryopreservation. The cell outgrowth from the explants of cryopreserved pulp fragments was two days later than that of corresponding fresh pulp tissue. Otherwise, no difference was observed in proliferation, expression of stem cell markers and differentiation into adipose cells and osteoblasts between the two groups of cells cultured from the fresh or the cryopreserved pulp fragments.

Conclusions Cryopreservating fragmented dental pulp tissue therefore provides a feasible option for saving pulp tissues as autologous cells sources for possible later application.

\section{Background}

Dental pulp cells exhibit features of stem cells and therefore provide a valuable cell source for tissue engineering and regeneration medicine [1].These cells can be obtained from wisdom teeth and any other teeth which are extracted for medical indications $[2,3]$. For the patients, cells derived from their own teeth are autologous which will not cause host rejection in potential later application [4]. Dental pulp cells are vital, grow fast, easy to handle in culture and exhibit high potential in multiple lineage differentiation especially into the osteogenic, adipogenic and condrogenic lineages [5]. With their neural crest origin, dental pulp cells exhibit even high neurogenic differentiation potential than bone marrow mesenchymal stem cells and therefore may be especially valuable for neuro-regeneration [6].

Cultured dental pulp cells can be cryopreserved for long term and used for studies and applications at any time later [7]. However, conventional cryopreservation with $10 \%$ DMSO is usually applied for single cells cultured in the laboratories [8]. To obtain such single cells, corresponding facility and skilled stuffs are demanded which are however only available for limited hospitals and clinics. Though many people will likely have some of their teeth extraction during their life, teeth have to be disposed as waste whereas they could provide valuable autologous sourced for these patients for possible future application.

To solve this problem and to enable culturing pulp cells for more patients, cryopreservation of dental pulp tissues at surgery may provide a strategy. Indeed, cryopreservation has been shown to be feasible for storing adipose tissues for 4 to 6 weeks from which vital cells can be successfully cultured later ([9]. 
Because the pulp tissues contain hardly any connecting tissues and the cells are loosely packed, we hypothesized that cryopreservation may also applicable to dental pulp tissues without damaging large portion of cells. When the pulp tissue is cut into small fragments, the cryo-protecting agent DMSO may penetrate the tissues well and enter the cells as in the case of a single cell suspension. The present study is designed to test our hypothesis and to examine the feasibility of cryopreservating pulp tissues at the site of teeth extraction. Paired fresh pulp tissue and cryopreserved ones were used for culturing pulp cells in identical experimental setting. Outgrowth from the tissue explants, morphology, proliferation, expression of stem cell markers and differentiation potentials of the cells derived from the two difference sources were comparatively studied.

\section{Methods}

\section{Specimen}

A total of 10 supernumerary and deciduous teeth of healthy children aged 10-15 years were collected from 2018 to 2019 in the department of orthodontics and children's stomatology of the affiliated stomatological hospital of Hebei medical university. According to the local regulation for privacy protection, all specimens used for the study were anonymized. Patients signed the informed consent and were instructed to gargle with a $1 \%$ hydrogen peroxide solution before the tooth extraction. The surgeon conducted a routine disinfection around the mouth. After the extraction, the teeth were kept in a DPBS solution supplemented with $2 \times 10^{5} \mathrm{U} / \mathrm{L}$ penicillin and streptomycin at $4^{\circ} \mathrm{C}$ medium for up to 4 hours.

\section{Cryopreservation of the pulp tissue fragments}

Each tooth was rinsed with DPBS solution several times before a hole was drilled into the root. The pulp tissue was pulled out with a tweezer and immersed into DMEM medium in a culture dish where it was cut into small pieces of approximately $0.5 \mathrm{~mm}^{3}$ (Fig. 1). The pulp tissue fragments were divided into 2 parts: one as fresh pulp tissue for immediate culturing and the other part for cryopreservation (Fig. 1). Cryopreservation was carried out by adding dimethyl sulfoxide (DMSO) to a final concentration of $10 \%$, cooling down the $1.6 \mathrm{ml}$ suspension in a $4{ }^{\circ} \mathrm{C}$ refrigerator for 1 hour, slowly freezing to $-80{ }^{\circ} \mathrm{C}$ overnight in a freezing container and finally storing in liquid nitrogen for at least one month.

\section{Thawing the cryo-preserved tissue fragments and culturing cells}

The tube containing the $1.6 \mathrm{ml}$ cryopreserved suspension of the pulp tissue fragments was taken out from the liquid nitrogen and immediately placed into a water bath of $37^{\circ} \mathrm{C}$. The cells were thawed within one minute and then slowly transferred to a culture dish with $15 \mathrm{ml}$ pre-warmed medium. Fresh pulp tissue fragments without cryopreservation was used for culturing cells in the same way (Fig. 1). The medium was changed on the next day. Then the dishes were kept in the incubator for two days. It is important not to move the dishes during these first two days to enable the pulp tissue explants to attach 
the cultural surface. From day 3 , the dishes were checked daily under a microscope to follow the outgrowth of the cells from the explants. The day for first cell outgrowth was recorded. By confluence of $70-80 \%$, the cells in monolayer were harvested with $0.125 \%$ trypsin, counted and passaged.

\section{Characterization Of The Pulp Cells}

Cell viability was measured using a MTS kit following the instruction of the supplier.

Cells in passage 3 were used for labelling with antibodies for surface markers of stem cells including stro-1, CD105, CD90, CD34 and CD45. The cell suspension was adjusted to a density of $1 \times 10^{9} / \mathrm{L}$ and passed through a $70 \mu \mathrm{m}$ filter. After 30 minutes incubation at $4^{\circ} \mathrm{C}$ in darkness, the labelled cells were analyzed on a flow-cytometry device.

\section{Differentiation}

Cells in the 3rd passage were seeded at density of $8 \times 10^{3} / \mathrm{ml}$ and grew to $70-80 \%$ confluence. Then the media were changed to adipogenic (with additives of $10 \mathrm{mg} / \mathrm{ml}$ insulin, $0.5 \mathrm{mM}$ methylxanthine, $1 \mathrm{mM}$ dexamethasone, $0.1 \mathrm{mM}$ indomethacin) or osteogenic (with additives of $10 \mathrm{mM} \beta$-glycerophosphat, $0.05 \mathrm{mM}$ vitamin C, $0.1 \mathrm{mM}$ dexamethasone) inducing media and the differentiation was continued for 3 weeks. At the end of the differentiation, the cells were stained with $0.5 \%$ oil red 0 or $2 \%$ Alizarin red $S$ to visualize oil droplets and mineral sediments produced by adipose cells and osteoblasts, respectively.

\section{Resuls}

\section{Cell Outgrowth And Proliferation}

For all the 10 cryopreserved dental pulp tissue fragments included in this study, vital cells were obtained which migrated from the explants from around day 7 (Fig. 2A, right). For fresh pulp tissues (Fig. 2A, left), cell outgrowth was approximately 2-day earlier (Fig. 2B). However, once the cells migrated out and grew in monolayer, same spindle, triangle and long spindle morphologies were observed for tissue fragments with and without cryopreservation (Fig. 3A). Also growth curves of the cells from the two groups of tissue fragments were compatible (Fig. 3B).

\section{Expression Of Stem Cell Markers}

Flow cytometry analysis revealed compatible expression of 5 stem cell markers (CD105, CD90, CD 45, CD34 and stro-1) in cells from the pulp tissue fragments with and without cryopreservation. In both groups, approximately $70 \%$ of the cells were positive for CD105 and CD 90 . However, less than $10 \%$ of the cells were positive for CD34, CD45 and stro-1 (Fig. 4). 


\section{Multipotential In Differentiation}

Dental pulp cells all exhibited potential of adipogenic and osteogenic differentiation regardless of cryopreservation. Oil-droplets were clearly visible in cells under adipogenic induction (Fig. 5) and mineral sediment in cells under osteogenic induction (Fig. 6). No difference was visible between the two groups of cells cultured using the fresh and cryopreserved tissue fragments. By contrast, no oil droplets nor mineral sediments were seen in the control primary gingival fibroblasts under the same inducing conditions, suggesting that the differentiation is a specific feature of the pulp cells, again, regardless of cryopreservation (Fig. 5, 6).

\section{Discussion}

In the present study, we demonstrated the feasibility of cryopreserving human dental pulp tissue fragments from which vital cells can be cultured later. The cells cultured from the cryopreserved tissue fragments exhibited compatible proliferation and differentiation potential as cells cultured from their fresh counterparts. The difference between the two groups was the two-days delay in cell-outgrowth for the cryopreserved explants.

Since the cultures are still in their 3-5 passages, we do not have the data at present for the total yield of cells. However, we expect that some cells will be damaged in cryopreservation process and consequently, the total yield will not be as good as in the case of fresh tissues. Further studies need to address this issue.

A possible explanation for our success in obtaining vital cells from the cryopreserved pulp tissue fragments may be the loose packing structure of the pulp cells in the pulp tissue which allows sufficient penetration of the cryoprotecting agent DMSO as in the case of a single cell suspension. For other tissues, this strategy may not be feasible. In the present study, our aim was to obtain single cells for culture. Therefore, it was not essential to maintain the original structure and cell organization of the tissue. However, structure and cell organization may have been altered in the cryopreservation process and that may one reason for the delayed cell outgrowth from the one cryopreserved explants.

Despite the slightly delayed outgrowth, once vital cells were obtained from cryopreserved tissue fragments, similar features were expected for them as for the cells from fresh tissue fragments. We indeed observed compatible features in the paired fresh/cryopreserved tissue fragments as regarding proliferation, and adipogenic and osteogenic differentiation. Importantly, such differentiation was completely absent in the fibroblasts which were included as a negative control under the identical differentiation conditions, providing strong supporting evidence that the observed differentiation is specific for the human dental pulp cells.

Since the primary aim of present study was to test the feasibility of cryopreservation of fragmented pulp tissues for later culturing vital cells, cutting the pulp tissues into fragments were carried out in the laboratory under a sterile culture bench to prevent contamination. In an ongoing study, we are testing the 
feasibility of preparing pulp tissues under standard clinical setting without a laboratory sterile bench. Should at least some of the pulp tissues survive the potential infection, preservation will be feasible at the teeth extraction in any dental and oral clinic. The only necessary device is a home-hold $-20^{\circ} \mathrm{C}$ freezer for temporal storing the tissue fragments which can be transported to a $-80^{\circ} \mathrm{C}$ freezer later at any time of convenience and finally into the liquid nitrogen for long term preservation.

\section{Conclusion}

In summary, our study demonstrated that vital cells can be cultured from cryopreserved dental pulp tissue when cut into small fragments. Proliferation and differentiation potentials of these cells were sustained. Using this strategy, substantially more patients will have the option of saving their pulp tissues as an autologous cells sources for possible later application.

\section{Abbreviations}

DMSO

dimethyl sulfoxide

\section{Declarations}

\section{Ethics approval and consent to participate}

Administrative permissions were acquired by our team to access the data used in our research. The study protocol was approved by the Hebei Medical University ethics committee that approved the study. No: 2018002. Accordingly, all teeth were coded with number and all personal identification of the patients were removed. All parent or guardian of participants provided written informed consent for using their teeth which otherwise would have been discarded as waste.

\section{Consent to publish}

Not applicable.

\section{Availability of data and materials}

The data are available from the corresponding author on reasonable request.

\section{Competing interests}

The authors declare that they have no competing interests.

\section{Funding}

Name: The key research and development project of Hebei Province Department of Science and Technology. Number17277745D 
The funding had played a role in payment of the reagent [dimethyl sulfoxide (DMSO, Sigma)].

\section{Authors' contributions}

MY: conceived the study, supervised the experiments and drafted the manuscript.

LK: performed the data collection and drafted the manuscript.

XLiu: designed the experiments and drafted the manuscript.

RS: performed the data collection.

PS: analyzed the data.

GR: data evaluation, manuscript preparation

XLi: data evaluation, manuscript preparation

MG: analyzed the data and revised the manuscript.

All authors have read and approved the manuscript

all authors have read and approved the manuscript, and ensure that this is the case.

\section{Acknowledgements}

Not applicable

\section{References}

1. Gronthos S, Mankani M, Brahim J, Robey PG, Shi S. Postnatal human dental pulp stem cells (DPSCs) in vitro and in vivo. Proc Natl Acad Sci U S A. 2000;97(25):13625-30.

2. Aydin S, Sahin F. Stem Cells Derived from Dental Tissues. Adv Exp Med Biol. 2019;1144:123-32.

3. Dehghani Nazhvani A, Ahzan S, Hosseini SM, Attar A, Monabati A, Tavangar MS. Purification of Stem Cells from Oral Pyogenic Granuloma Tissue. Open Dent J. 2018;12:560-6.

4. Wang Z, Pan J, Wright JT, Bencharit S, Zhang S, Everett ET, Teixeira FB, Preisser JS. Putative stem cells in human dental pulp with irreversible pulpitis: an exploratory study. J Endod. 2010;36(5):8205.

5. Chalisserry EP, Nam SY, Park SH, Anil S. Therapeutic potential of dental stem cells. J Tissue Eng. 2017;8:2041731417702531.

6. Young F, Sloan A, Song B. Dental pulp stem cells and their potential roles in central nervous system regeneration and repair. J Neurosci Res. 2013;91(11):1383-93. 
7. Fabricant L, Kiraly L, Wiles C, Differding J, Underwood S, Deloughery T, Schreiber M. Cryopreserved deglycerolized blood is safe and achieves superior tissue oxygenation compared with refrigerated red blood cells: a prospective randomized pilot study. J Trauma Acute Care Surg. 2013;74(2):371-6. discussion 376-7.

8. Xu X, Cowley S, Flaim CJ, James W, Seymour LW, Cui Z. Enhancement of cell recovery for dissociated human embryonic stem cells after cryopreservation. Biotechnol Prog. 2010;26(3):781-8.

9. Zanata F, Bowles A, Frazier T, Curley JL, Bunnell BA, Wu X, Wade J, Devireddy R, Gimble JM, Ferreira LM. Effect of Cryopreservation on Human Adipose Tissue and Isolated Stromal Vascular Fraction Cells: In Vitro and In Vivo Analyses. Plast Reconstr Surg. 2018;141(2):232e-243e.

\section{Figures}




\section{Figure 1}
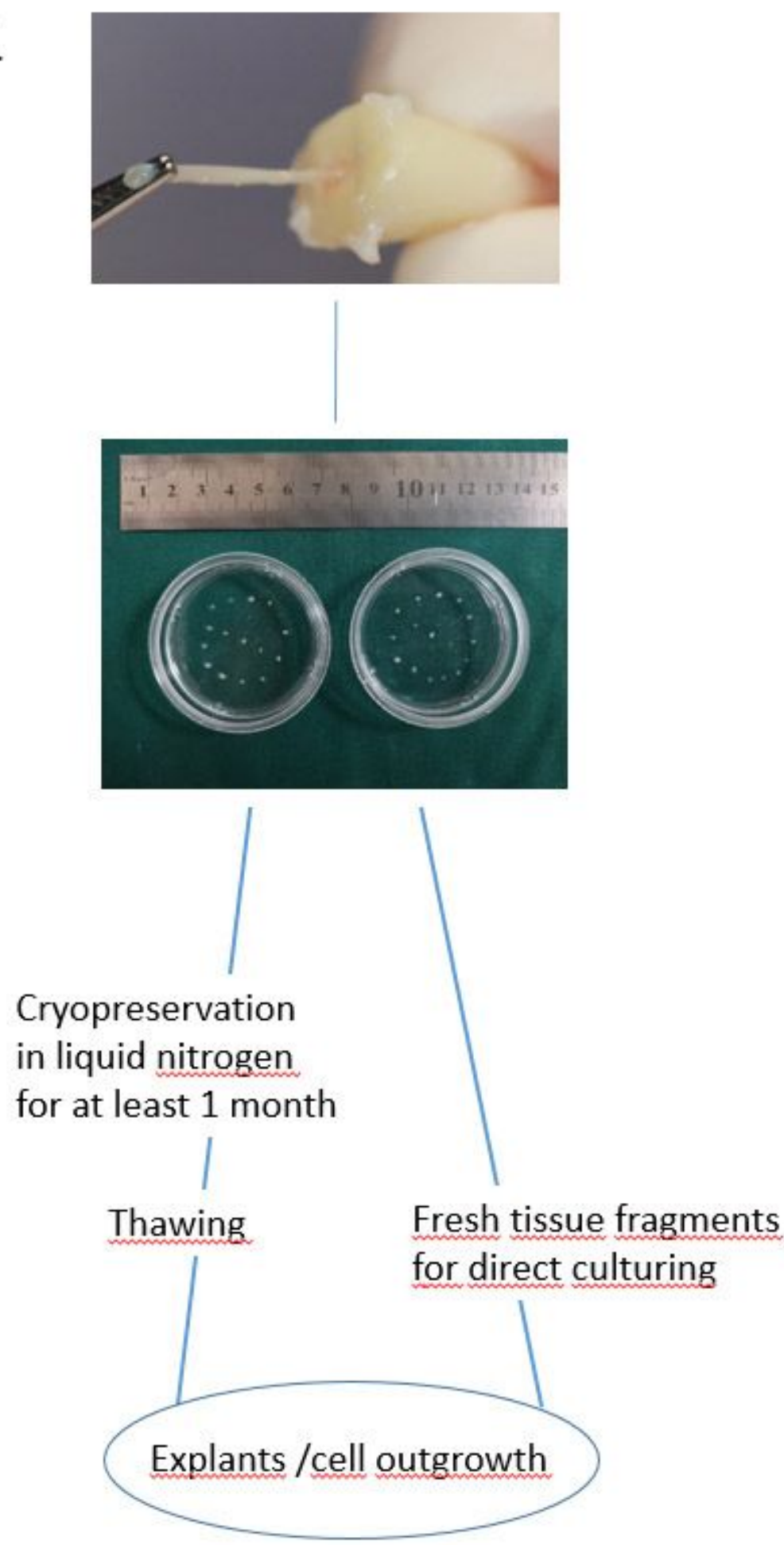

Figure 1

An illustration of the procedure. A dental pulp pulled out from a tooth was cut into small fragments in medium. The fragment suspension was divided into two parts, one as fresh tissue for immediate culturing and the other for cryopreservation which was thawed later and used for culturing. 
Figure 2

A

Cryopreserved

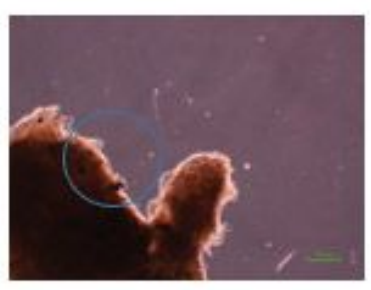

day 7

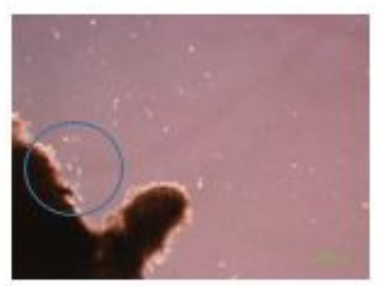

Day 7

(enlarged)

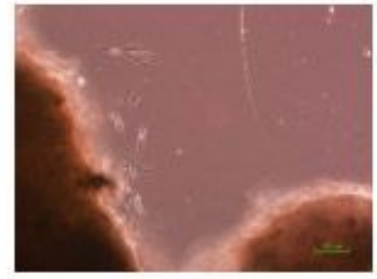

Immediate culturing

Day 4

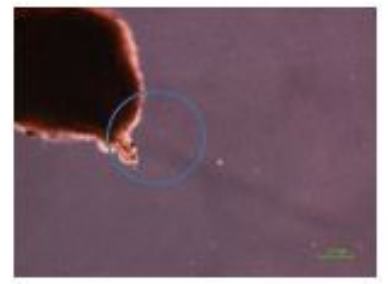

Day 5

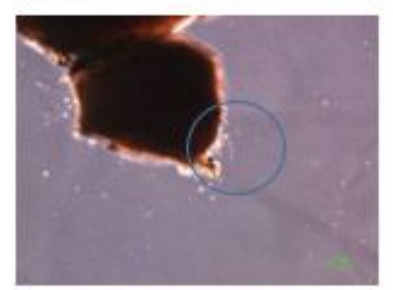

Day 5

(enlarged)

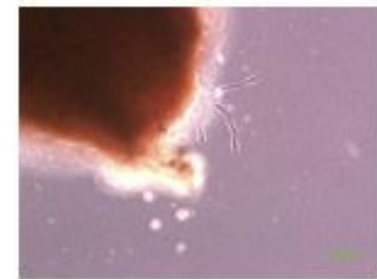

B

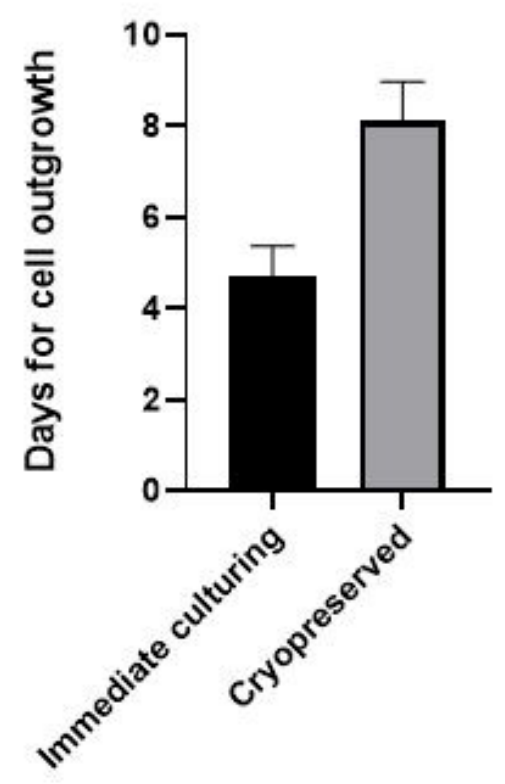

\section{Figure 2}

A: Cell outgrowth from paired cryopreserved (left) and fresh (right) fragments of dental pulp tissues. For the former, cell growing out of the explants were visible in the circled area on day 7 . Note that no cells were visible one day before (day 6 ) in the same circled area. For fresh pulp tissue, cell outgrowth started two-day earlier, on day 5. B: days from seeding to cell outgrowth for the 10 paired cryopreserved and fresh pulp fragments. 
Figure 3

A
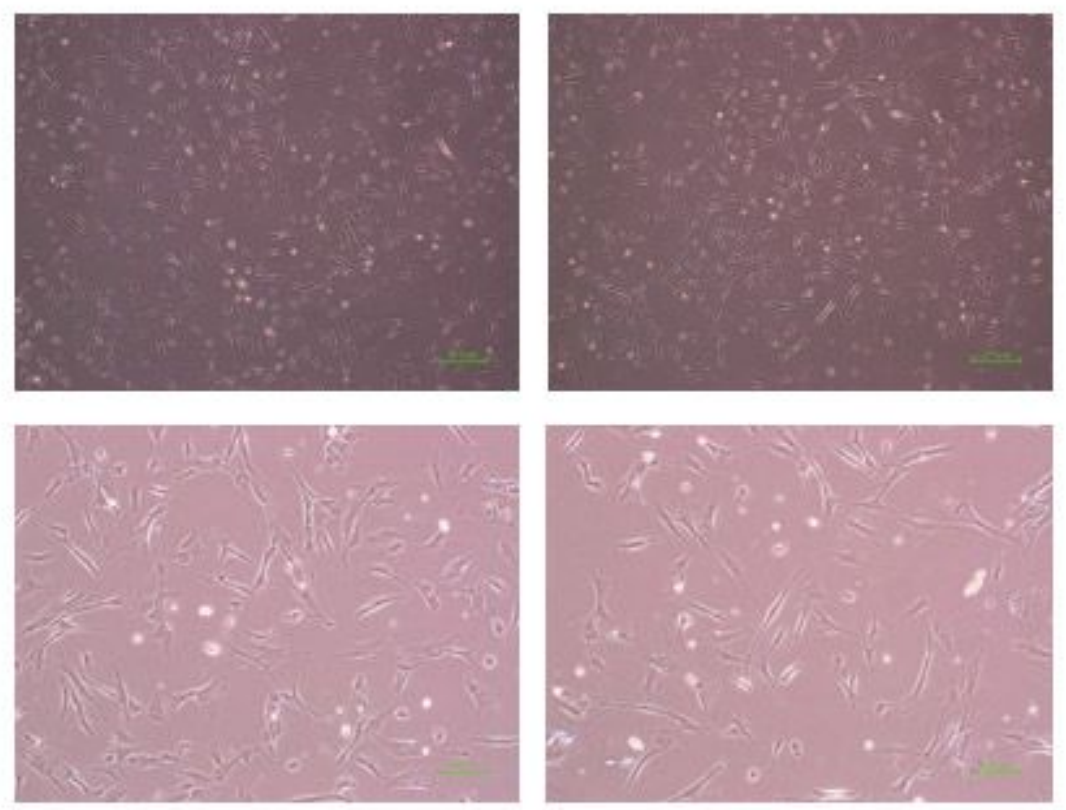

B

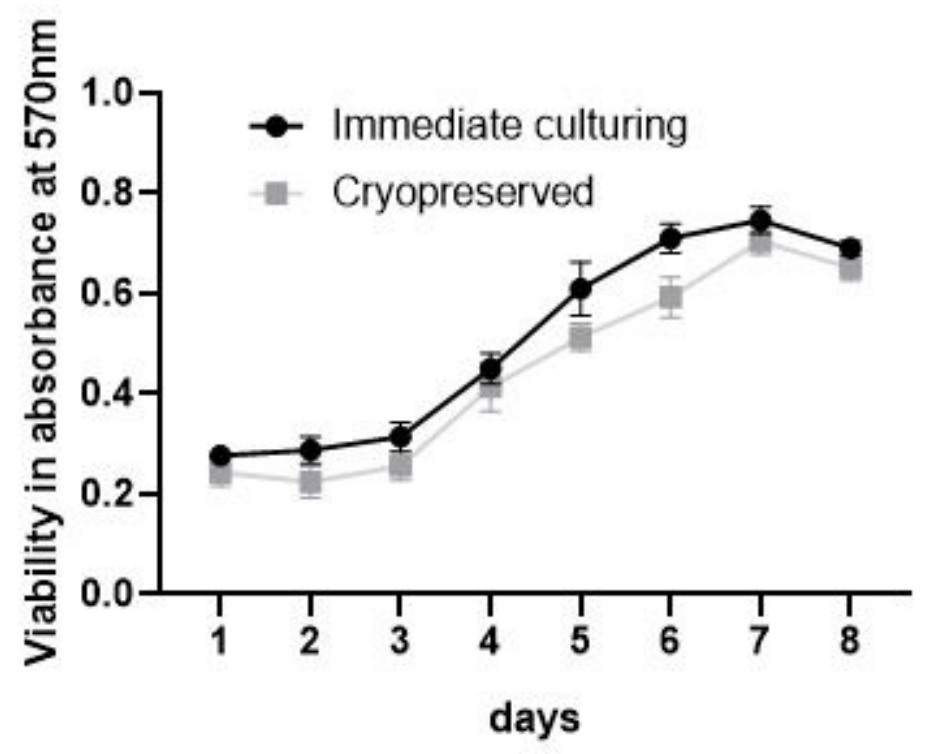

Figure 3

A: Cells in monolayer in the 2 nd passage. No difference in morphology was visible between the two groups. B: Growth curve of cells from the 10 pairs of fresh/cryopreserved pulp tissue fragments. 
Figure 4

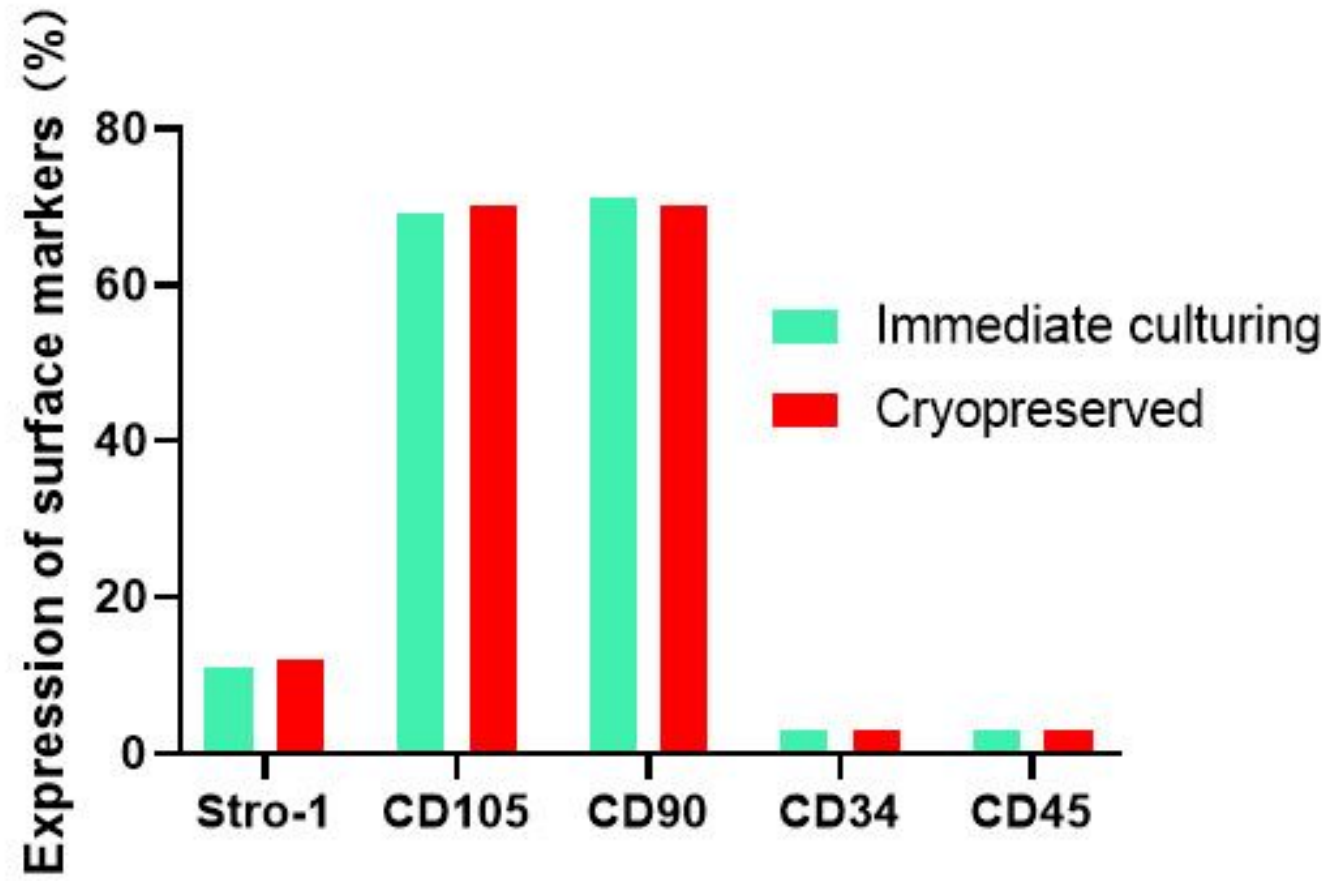

Figure 4

Nearly identical expression of stem markers in cells from the paired fresh/cryopreserved pulp tissue fragments. 
Figure 5

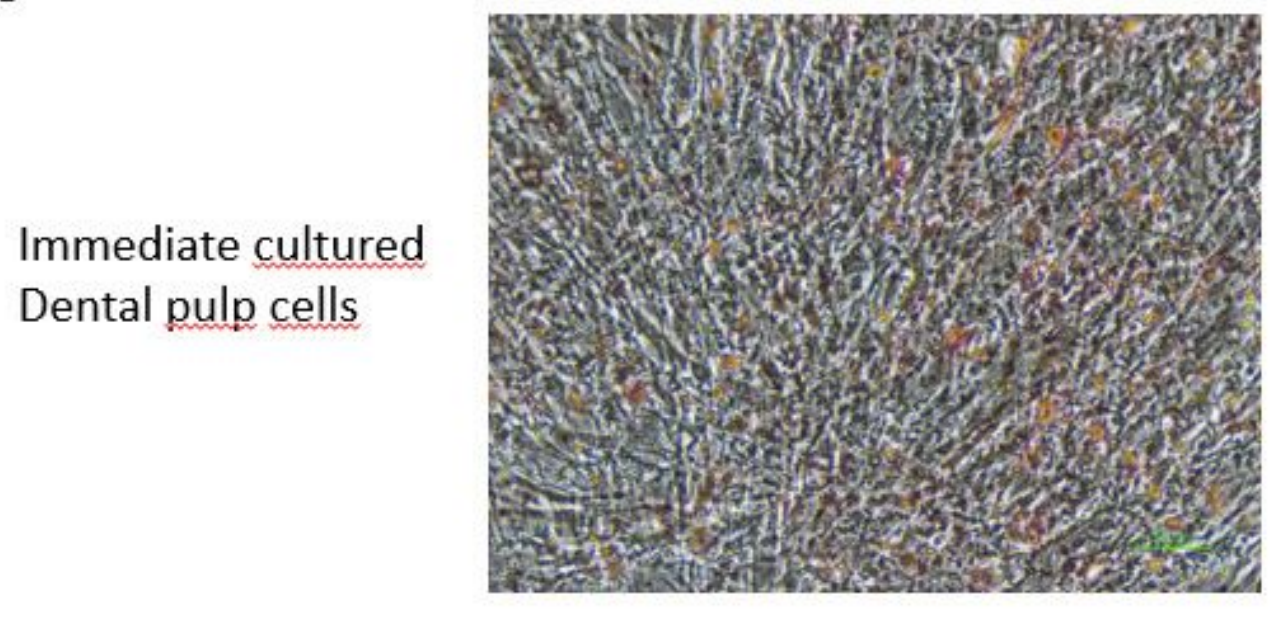

Cryopreserved

Dental pulp cells

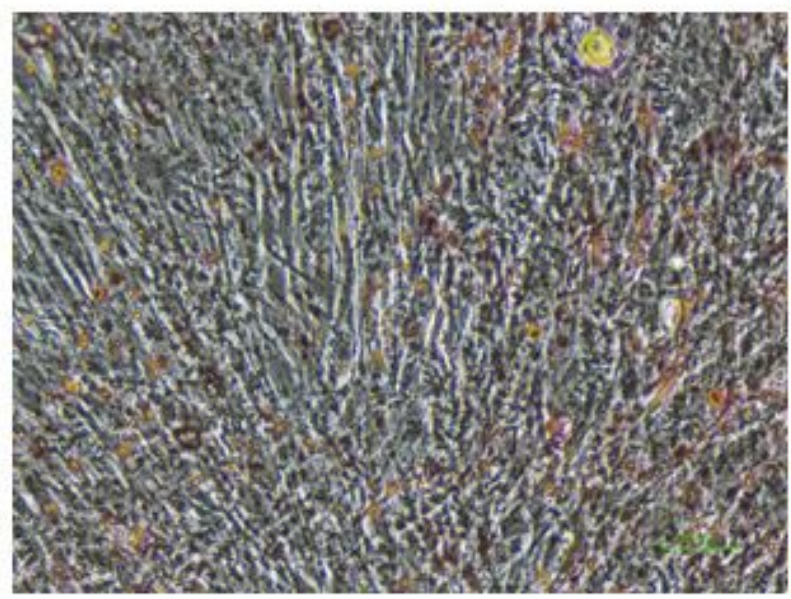

Primary fibroblasts

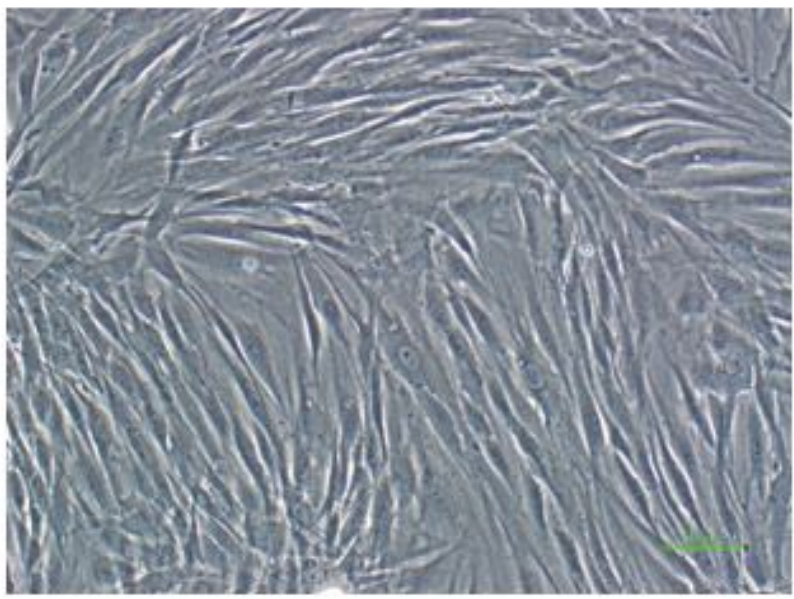

\section{Figure 5}

Nearly identical expression of stem markers in cells from the paired fresh/cryopreserved pulp tissue fragments. 
Figure 6

Immediate cultured

Dental pulp cells

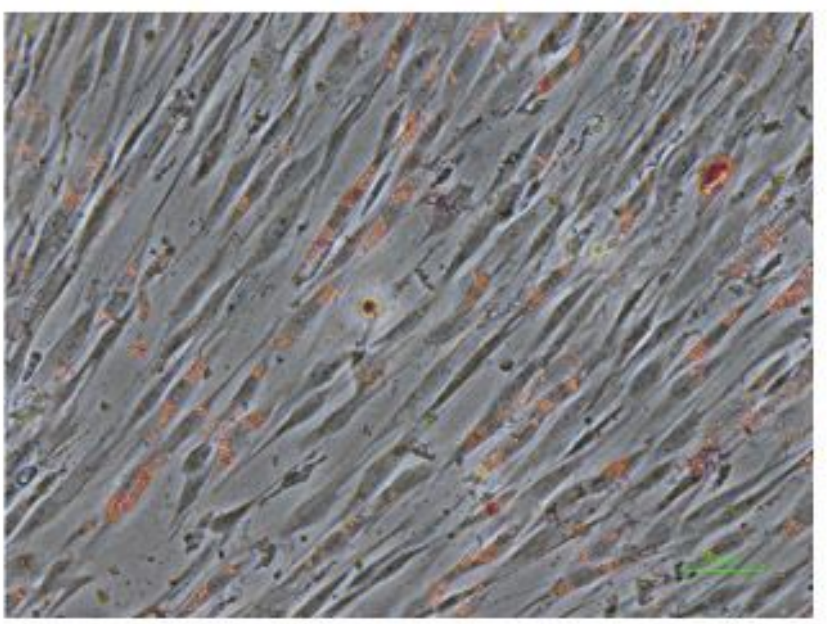

Cryopreserved

Dental pulp cells

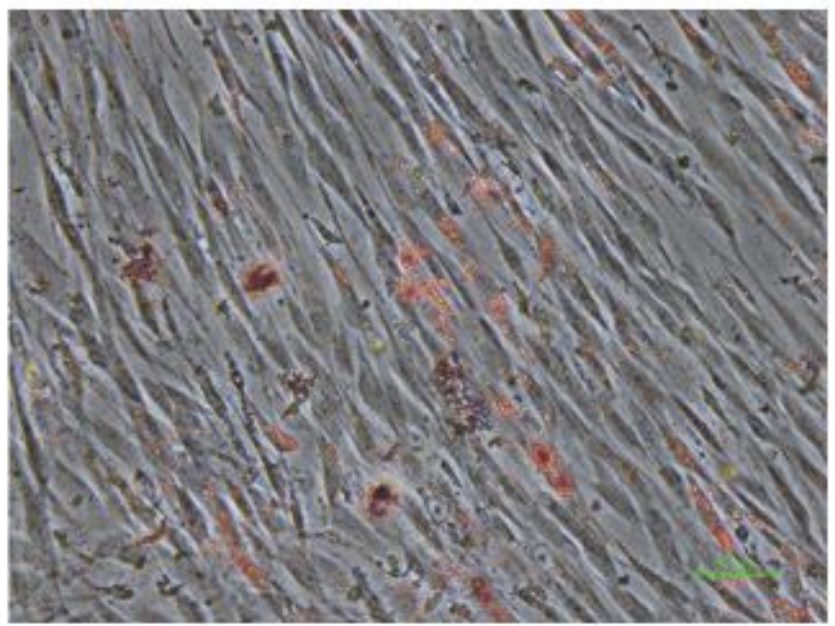

Primary fibroblasts

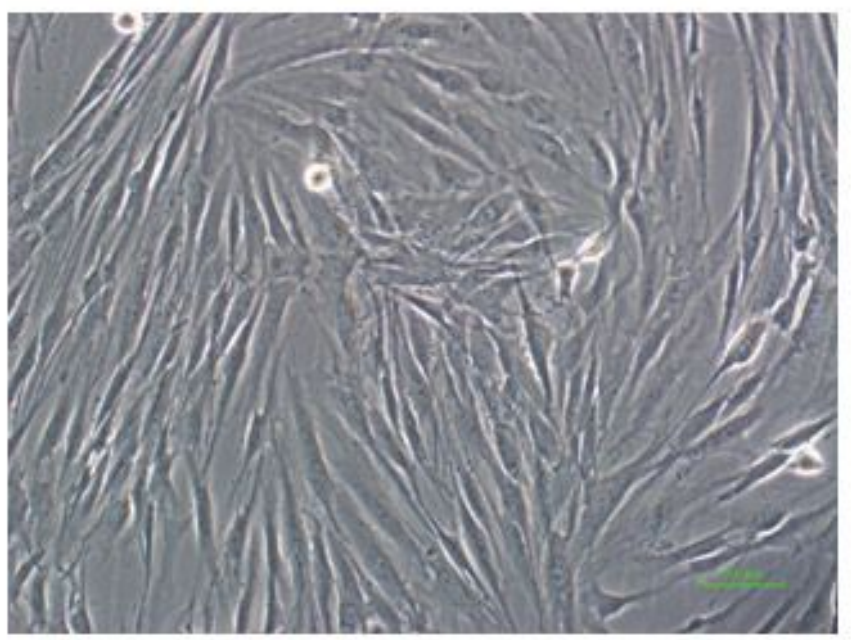

\section{Figure 6}

Osteogenic differentiation of cells from paired fresh/cryo-preserved pulp tissue fragments. Mineral sediments stained with Alzerin were clearly visible. Human gingival fibroblasts in primary culture were included as a negative control. 